\title{
Gas phase synthesis of non-bundled, small diameter single-walled carbon nanotubes with near-armchair chiralities
}

Cite as: Appl. Phys. Lett. 107, 013106 (2015); https://doi.org/10.1063/1.4926415

Submitted: 12 May 2015. Accepted: 26 June 2015 . Published Online: 09 July 2015

K. Mustonen, P. Laiho, A. Kaskela, Z. Zhu, O. Reynaud, N. Houbenov, Y. Tian, T. Susi (D), H. Jiang, A. G. Nasibulin, and E. I. Kauppinen

\section{ARTICLES YOU MAY BE INTERESTED IN}

Uncovering the ultimate performance of single-walled carbon nanotube films as transparent conductors

Applied Physics Letters 107, 143113 (2015); https://doi.org/10.1063/1.4932942

Large-scale and low-cost synthesis of single-walled carbon nanotubes by the catalytic pyrolysis of hydrocarbons

Applied Physics Letters 72, 3282 (1998); https://doi.org/10.1063/1.121624

Conductivity scaling with bundle length and diameter in single walled carbon nanotube networks

Applied Physics Letters 89, 133112 (2006); https://doi.org/10.1063/1.2356999 


\title{
Gas phase synthesis of non-bundled, small diameter single-walled carbon nanotubes with near-armchair chiralities
}

\author{
K. Mustonen, ${ }^{1}$ P. Laiho, ${ }^{1}$ A. Kaskela, ${ }^{1}$ Z. Zhu, ${ }^{1}$ O. Reynaud, ${ }^{1}$ N. Houbenov, ${ }^{1}$ Y. Tian, ${ }^{1}$ \\ T. Susi, ${ }^{2}$ H. Jiang, ${ }^{1}$ A. G. Nasibulin, ${ }^{1,3,4}$ and E. I. Kauppinen ${ }^{1, a)}$ \\ ${ }^{1}$ Department of Applied Physics, Aalto University School of Science, P.O. Box 15100, FI-00076 Aalto, Finland \\ ${ }^{2}$ Faculty of Physics, University of Vienna, Boltzmanngasse 5, A-1090 Vienna, Austria \\ ${ }^{3}$ Skolkovo Institute of Science and Technology, Nobel str. 3, 143026, Russia \\ ${ }^{4}$ Saint-Petersburg State Polytechnical University, 29 Polytechniheskaya st., St. Petersburg, 195251, Russia
}

(Received 12 May 2015; accepted 26 June 2015; published online 9 July 2015)

\begin{abstract}
We present a floating catalyst synthesis route for individual, i.e., non-bundled, small diameter single-walled carbon nanotubes (SWCNTs) with a narrow chiral angle distribution peaking at high chiralities near the armchair species. An ex situ spark discharge generator was used to form iron particles with geometric number mean diameters of 3-4 nm and fed into a laminar flow chemical vapour deposition reactor for the continuous synthesis of long and high-quality SWCNTs from ambient pressure carbon monoxide. The intensity ratio of G/D peaks in Raman spectra up to 48 and mean tube lengths up to $4 \mu \mathrm{m}$ were observed. The chiral distributions, as directly determined by electron diffraction in the transmission electron microscope, clustered around the $(\mathrm{n}, \mathrm{m})$ indices $(7,6),(8,6),(8,7)$, and $(9,6)$, with up to $70 \%$ of tubes having chiral angles over $20^{\circ}$. The mean diameter of SWCNTs was reduced from 1.10 to $1.04 \mathrm{~nm}$ by decreasing the growth temperature from 880 to $750{ }^{\circ} \mathrm{C}$, which simultaneously increased the fraction of semiconducting tubes from $67 \%$ to $80 \%$. Limiting the nanotube gas phase number concentration to $\sim 10^{5} \mathrm{~cm}^{-3}$ prevented nanotube bundle formation that is due to collisions induced by Brownian diffusion. Up to $80 \%$ of 500 asdeposited tubes observed by atomic force and transmission electron microscopy were individual. Transparent conducting films deposited from these SWCNTs exhibited record low sheet resistances of $63 \Omega / \square$ at $90 \%$ transparency for $550 \mathrm{~nm}$ light. @ 2015 AIP Publishing LLC.
\end{abstract}

[http://dx.doi.org/10.1063/1.4926415]

Many electronic applications of single-walled carbon nanotubes (SWCNTs), including field effect transistors (FETs) — both single-tube ${ }^{1}$ and percolating ${ }^{2}$ —and nanoelectromechanical systems, ${ }^{3}$ benefit from clean, high-quality, and non-aggregated SWCNTs. Although catalysts are mostly immobile in substrate-supported chemical vapor deposition (CVD) techniques, enabling the growth of well-separated tubes, ${ }^{4}$ usable support substrates are mainly limited to oxides that are able to withstand elevated temperatures required by the SWCNT growth. This prevents in situ growth on temperature sensitive substrates required, e.g., by flexible and transparent conductive films (TCFs), necessitating additional dispersion and deposition steps that often lead to a degradation of the tubes' intrinsic properties due to the use of chemical surfactants and tube cutting during sonication. ${ }^{5}$

For such applications and for many fundamental studies, floating catalyst CVD (FC-CVD) methods such as high pressure CO disproportionation ${ }^{6}$ (HiPco) and ferrocene vapor decomposition ${ }^{7}$ offer distinct advantages, for they provide a possibility to directly deposit high quality SWCNTs onto any substrate. $^{8}$ However, apart from using post-synthesis electrostatic filtration to remove electrically charged bundles from the aerosol flow, ${ }^{9}$ these methods have so far failed to overcome the bundle formation issue, which has limited their usefulness.

We attribute this drawback to the lack of efficient means for controlling the gas phase number concentration $(\mathrm{N})$ of

a)Electronic mail: esko.kauppinen@aalto.fi
SWCNTs during growth, which leads to mutual collisions and bundle formation due to Brownian diffusion. This collision rate of aerosol particles is related to mobility diameter $\left(D_{M}\right)$, ambient temperature $(T)$, and carrier gas viscosity $(\eta)$ through $^{10}$

$$
\frac{d N}{d t}=-K\left(D_{M}, T, \eta\right) N^{2},
$$

where $\mathrm{K}$ is the coagulation coefficient. Since in a particular growth condition, the dimensions of the nanotubes and the temperature do not vary, the collision rate is simply proportional to $\mathrm{N}^{2}$. Unfortunately, the mobility diameters of SWCNTs are not directly known, although, e.g., Kim and Zachariah have estimated that multiwalled CNTs of $15 \mathrm{~nm}$ diameters and $100-700 \mathrm{~nm}$ lengths have $\mathrm{D}_{\mathrm{M}}$ of approximately $50-120 \mathrm{~nm}^{11}$ For SWCNTs with similar lengths, these are likely crude overestimates, as for non-isometric fibrous structures the diameter is an important parameter defining the mobility. ${ }^{12}$ Thus, we estimate the $D_{M}$ for SWCNTs of around $10-30 \mathrm{~nm}$, resulting in coagulation coefficients between $2.6 \times 10^{-9}$ and $9.0 \times 10^{-9} \mathrm{~cm}^{3} \mathrm{~s}^{-1}$, therefore implying that in the reactor the number concentration should be kept well below $10^{6} \mathrm{~cm}^{-3}$ to limit bundle formation during a typical $10 \mathrm{~s}$ gas flow residence time.

The floating catalyst CVD technique we present here was designed to control $\mathrm{N}_{\mathrm{CNT}}$ by decoupling the catalyst and nanotube growth steps into two subsequent processes. The catalyst particles are formed by a spark discharge generator ${ }^{13}$ 


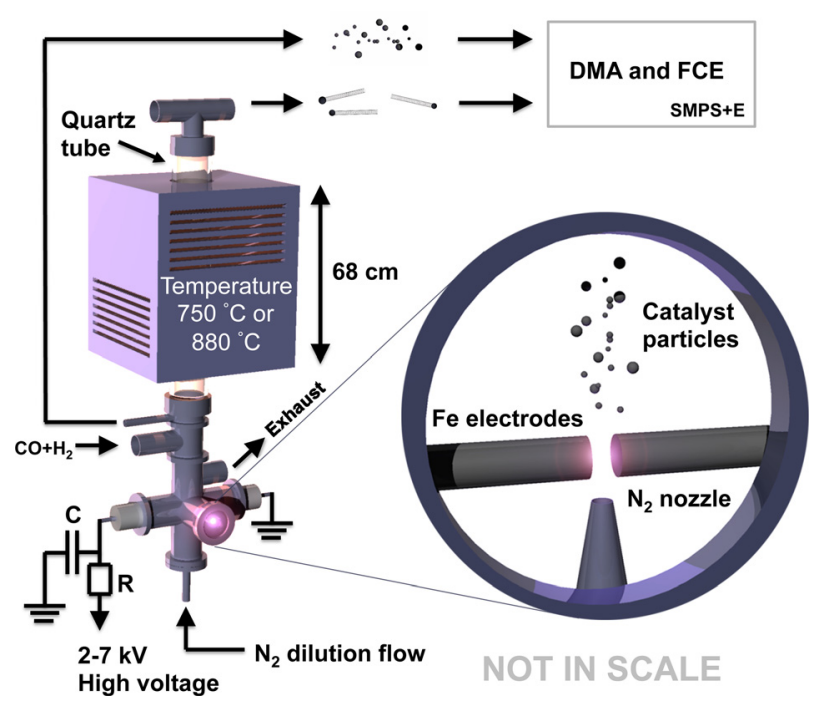

FIG. 1. A schema of the synthesis reactor. The spark generator consists of a pair of iron electrodes separated by a discharge gap, continuously flushed by a high-velocity $\mathrm{N}_{2}$ jet. The discharges evaporate metal from the electrodes, forming catalyst particles that are subsequently fed into the vertical CVD reactor consisting of a quartz tube in a high temperature furnace. A SMPS + E (scanning mobility particle sizer with electrometer) aerosol size classifier consisting of a differential mobility analyser (DMA) and Faraday cup electrometer (FCE) is used to determine the catalyst number concentrations $(\mathrm{N})$ and geometric mean diameter $\left(\mathrm{D}_{\mathrm{g}}\right)$ prior to introduction into the reactor, and those of the SWCNTs at the reactor outlet.

(Figure 1), in which Fe (purity 99.95\%, Goodfellow, UK) evaporates from a pair of rod-shaped electrodes (spacing $\mathrm{L}=0.5-1.0 \mathrm{~mm}$ and diameter $2-5 \mathrm{~mm}$ ), constantly flushed by a high velocity $\mathrm{N}_{2}$ jet (nozzle diameter of $2.5 \mathrm{~mm}$ and velocity of 200-1500 $\mathrm{ms}^{-1}$ ) held $4 \mathrm{~mm}$ from the gap. The spark discharge gap capacitance $(\mathrm{C}=0.47-47 \mathrm{nF})$ is recharged using a high-voltage source $(20 \mathrm{kV}$, Matsushita, Japan) through a ballast resistor $(\mathrm{R}=1.5 \mathrm{M} \Omega)$ until a discharge occurs and the process starts over. Hence, the recharge voltage (typically $2-7 \mathrm{kV}$ ) defines the recharge current and the discharge frequency (f, typically $0.1-1.0 \mathrm{kHz}$ ). The discharges between the electrodes generate plasma that evaporates the catalyst material. The electrode mass loss rate is proportional to the frequency of constant energy discharges, whereas the resulting mass concentration of $\mathrm{Fe}$ per unit volume of the $\mathrm{N}_{2}$ dilution gas is proportional to the volumetric flow rate (typically $\mathrm{Q}=6-45 \times 10^{3} \mathrm{~cm}^{3} \mathrm{~min}^{-1}$ ). Each discharge creates an approximately constant number $\left(\mathrm{n}_{0}\right)$ of primary particles, or condensation nuclei, and thus the number concentration of primary particles $\mathrm{N}_{\mathrm{p}}$ becomes ${ }^{13}$

$$
N_{p}=n_{0} \frac{f}{Q} .
$$

According to Schwyn et al., the geometric mean diameter $\left(D_{g}\right)$ of primary particles from such discharges is on the order of $1-2 \mathrm{~nm}$, while $\mathrm{n}_{0}$ is between $10^{5}$ and $10^{6}$ with a capacitance of $2.2 \mathrm{nF}$ and a gap of $1 \mathrm{~mm} .{ }^{13}$ However, regardless of the high volumetric dilution flow, the primary particles aggregate due to their extremely high Brownian diffusivity, resulting in a lognormal diameter distribution with a geometric mean diameter larger than $3 \mathrm{~nm}$.

Prior to introducing the catalyst particles into the CVD reactor, their number size distribution (NSD) is measured using a SMPS + E system (scanning mobility particle sizer with electrometer, GRIMM Aerosol Technic GmbH, Germany) consisting of a differential mobility analyzer (Vienna-type Nano-DMA, length of $15 \mathrm{~mm}$ ) and Faraday cup electrometer (FCE, sensitivity of $0.1 \mathrm{fA}$ ). Figure 2(a) shows typical catalyst NSDs at recharge voltages of 2.2, 2.8, and $3.2 \mathrm{kV}$. Practical experience operating the system has shown us that by adjusting $\mathrm{Q}, \mathrm{L}, \mathrm{f}, \mathrm{C}$, and recharge voltages, the geometric mean diameter $\mathrm{D}_{\mathrm{g}}$ can be tuned from $3 \mathrm{~nm}$ upwards. The catalyst collisions and the following aggregation, however, also set the practical upper limit of the CNT number concentration to $\sim 10^{6} \mathrm{~cm}^{-3}$; further increasing the concentration results in particle aggregate formation on the expense of nanotube yield. Figure 2(a) illustrates the tendency of particle growth together with the increasing number concentration. Thus, in order to both avoid significant deposits of inactive catalyst aggregates on the nanotubes and to prevent their bundling, the desired catalyst $D_{g}$ is between 3 and $4 \mathrm{~nm}$ and $N$ is between $10^{5}$ and $10^{6} \mathrm{~cm}^{-3}$.

Downstream from the spark generator, the particles carried by the flowing $\mathrm{N}_{2}$ (limited to $200 \mathrm{~cm}^{-3} \mathrm{~min}^{-1}$, the rest going to exhaust) are mixed with carbon monoxide (CO, $\left.250 \mathrm{~cm}^{-3} \mathrm{~min}^{-1}\right)$ and hydrogen $\left(\mathrm{H}_{2}, 50 \mathrm{~cm}^{-3} \mathrm{~min}^{-1}\right)$ and introduced into a laminar flow (Reynolds number-25) vertical CVD reactor consisting of a quartz tube (inner diameter a)

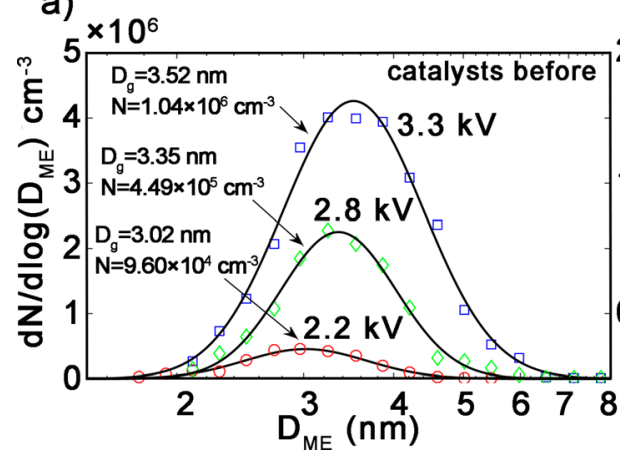

b)

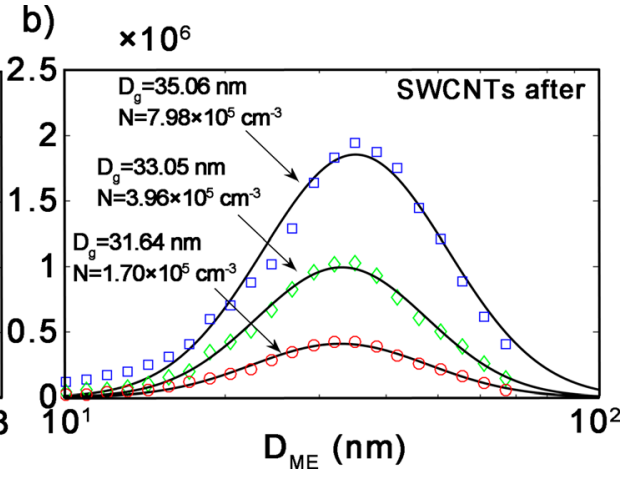

FIG. 2. Catalyst particle and SWCNT NSDs measured with the DMA with different spark generator settings. (a) Catalyst NSDs acquired with spark settings $\mathrm{C}=47 \mathrm{nF}, \mathrm{L}=0.5 \mathrm{~mm}, \mathrm{Q}=45 \mathrm{lpm}$, and $\mathrm{U}_{\mathrm{R}}=2.2,2.8$, and $3.3 \mathrm{kV}$, having geometric mean diameters $\left(\mathrm{D}_{\mathrm{g}}\right)$ of $3.02,3.35$, and $3.52 \mathrm{~nm}$, and corresponding number concentrations (N) of $9.60 \times 10^{4}, 4.49 \times 10^{5}$, and $1.04 \times 10^{6} \mathrm{~cm}^{-3}$, respectively. (b) The corresponding SWCNT NSDs, demonstrating a correlation between the catalyst and SWCNT number concentrations. $\mathrm{D}_{\mathrm{ME}}$ on the logarithmic x-axis is the electrical mobility diameter. 
of $22 \mathrm{~mm}$ ) placed inside a high-temperature furnace. The FC-CVD reactor flows were designed using computational fluid dynamics (CFD) calculations to prevent turbulence, as that may significantly increase the particle collision rate. ${ }^{10}$ (The CFD solutions are presented in Ref. 14.) For SWCNT growth, the reactor temperature is set either to 750 or $880^{\circ} \mathrm{C}$, where carbon is exclusively released through catalytic $\mathrm{CO}$ disproportionation and hydrogenation reactions on the surfaces of the catalysts, resulting in the growth of clean nanotubes. ${ }^{7,15}$ Crucially, the CNT number concentration is directly proportional to the concentration of catalyst in the active size range (Figures 2(a) and 2(b)) and can therefore be defined prior to synthesis.

Scanning electron microscopy (SEM, Zeiss Sigma VP) was used to deduce the SWCNT lengths from tubes thermophoretically ${ }^{16}$ deposited onto p-doped $\mathrm{Si} / \mathrm{SiO}_{2}$ wafers. The lengths exhibited the expected lognormal distributions ${ }^{8}$ with geometric means of $1.95 \mu \mathrm{m}$ for the growth temperature of $750{ }^{\circ} \mathrm{C}$ and $4.03 \mu \mathrm{m}$ for $880^{\circ} \mathrm{C}$, indicating an approximately two-fold difference in growth rates since the residence time in the reactor varies only slightly. The length distributions can be found in Ref. 14.

A high-resolution transmission electron microscope (TEM, $2 \times \mathrm{C}_{\mathrm{s}}$-corrected JEOL JEM-2200FS, JEOL Ltd., Japan) operated at $80 \mathrm{kV}$ was used to measure the tube diameters and bundle sizes, and chiral distributions determined via electron diffraction. For TEM characterization, the CNTs were directly deposited from the aerosol flow onto TEM grids using a collection time of 3 min with $\mathrm{N}$ set to $\sim 2 \times 10^{5} \mathrm{~cm}^{-3}$ to minimize gas phase collisions. According to TEM observations, the as-grown SWCNTs were clean and had relatively small mean diameters varying with growth temperature from $1.04 \pm 0.19 \mathrm{~nm}$ at $750^{\circ} \mathrm{C}$ to $1.10 \pm 0.26 \mathrm{~nm}$ at $880^{\circ} \mathrm{C}$, as shown in Figures 3(a)-3(d) and 3(f). The larger diameter at $880^{\circ} \mathrm{C}$ may be attributed to enhanced $\mathrm{CO}$ disproportionation, releasing more carbon to saturate slightly larger diameter catalyst particles which therefore become active for SWCNT growth. The mean diameters of the nanotubes were similar to $\mathrm{CoMoCat}^{17}$ and to $\mathrm{HiPco}^{6}$ at $\sim 0.8 \mathrm{~nm}$ and $\sim 1.0 \mathrm{~nm}$, respectively. Figures $3(\mathrm{~g})$ and $3(\mathrm{~h})$ and Table I show how the $(\mathrm{n}, \mathrm{m})$ distributions were clustered at high chiral angles around the $(7,6)$ and $(8,6)$ species at a growth temperature of $750{ }^{\circ} \mathrm{C}$ and near $(8,7)$ and $(9,6)$ at $880^{\circ} \mathrm{C}$; up to $67 \%$ of our tubes had chiral angles $\geq 20^{\circ}$, which is a significantly narrower angle distribution than that produced by the HiPco method. ${ }^{18}$ In fact, our chiral angle distributions were even narrower than those of CoMoCat SWCNTs, ${ }^{19,20}$ typically considered to have the narrowest distribution of all standard CVD methods. The observed fraction of semiconducting tubes in the $880^{\circ} \mathrm{C}$ sample was the expected $67 \%$, whereas the $750^{\circ} \mathrm{C}$ one had a larger fraction of $80 \%$.

Importantly, careful and systematic observations of the bundles deposited onto TEM grids revealed that $60 \%$ of the tubes were individual, strikingly different from other FCCVD methods reported in the literature. ${ }^{6,7,15}$ Moreover, while some small bundles were also present in the sample, only about $10 \%$ contained more than two individual tubes, as illustrated in Figure 3(e).

The TEM studies were supplemented by atomic force microscopy (AFM, Dimension 5000, Veeco Instruments,
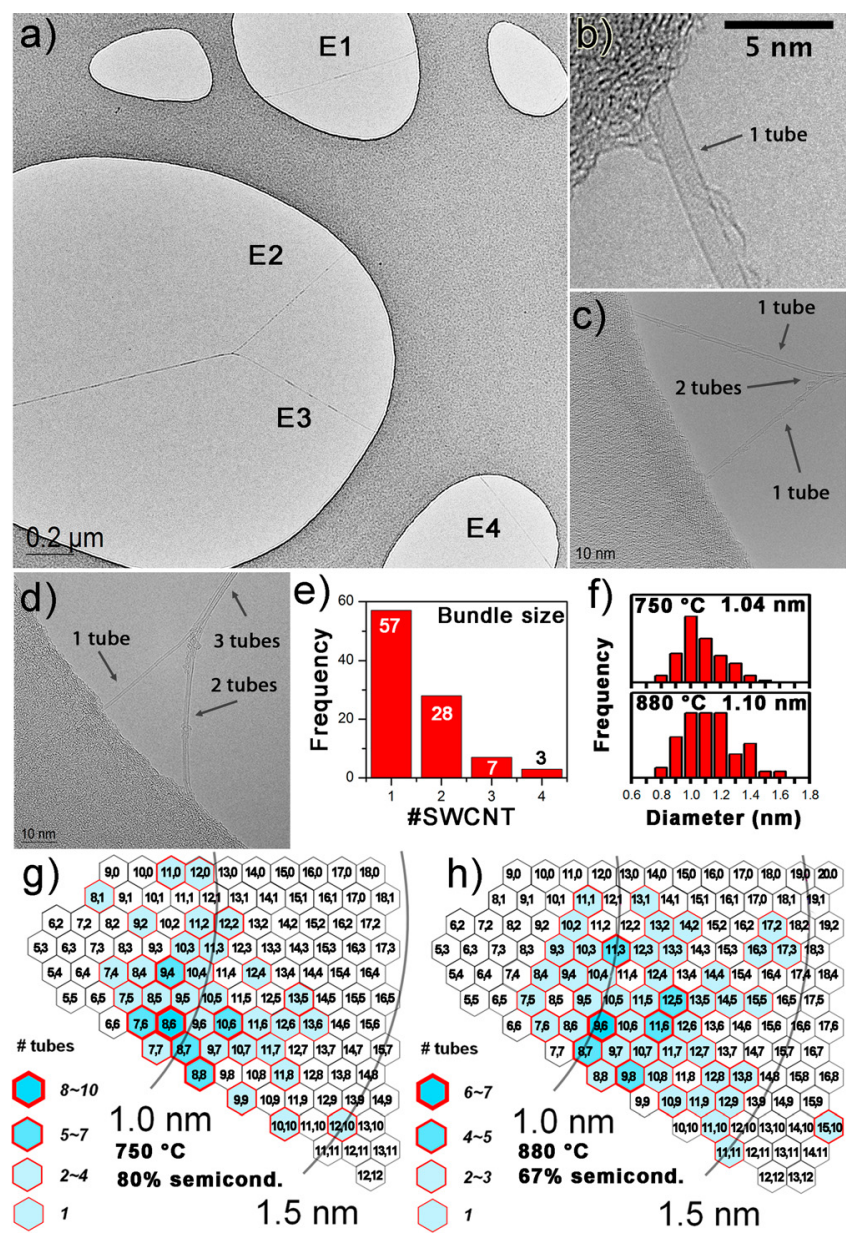

FIG. 3. TEM characterization of as-deposited SWCNTs. (a) An example of the typical SWCNT morphology with a 3 min collection time, exhibiting a high fraction of individual tubes. Electron diffraction patterns of the individual tubes E1-E4 are shown in Ref. 14. (b)-(d) Micrographs showing typical individual tubes and small bundles (2-3 tubes, synthesized at $880^{\circ} \mathrm{C}$ ), with very little surface contamination and (e) bundle size statistics showing $60 \%$ of individual tubes. (f) Diameter statistics of the tubes synthesized both at 750 and $880^{\circ} \mathrm{C}$, and $(\mathrm{g})$ and $(\mathrm{h})$ the chiral angle maps.

Inc., USA) of SWCNTs thermophoretically ${ }^{16}$ deposited onto mica substrates and imaged using settings optimized for nanotubes. ${ }^{21}$ In general, similar to TEM, the bundles and individual tubes were sparsely deposited and clearly resolved from the substrate, as is evident from Figure 4. The heights of the bundles are best illustrated via profiler tools (profiles 1-6 shown in Figure 4 and the rest in Ref. 14) drawn in the scan window. The representative sample of bundles in Figure 4 exhibits heights between 1 and $1.3 \mathrm{~nm}$, whereas a larger statistical sample $(n \approx 400)$ revealed a mean height of $1.21 \mathrm{~nm}$, with up to $80 \%$ of the bundles having heights $<1.4 \mathrm{~nm}$. Importantly, the bundle heights were almost

TABLE I. SWCNT chiral angle populations measured by electron diffraction ( $\sim 90$ tube statistics for each temperature for spark and 265 tubes for CoMoCat). ${ }^{19}$

\begin{tabular}{lccc}
\hline \hline & $10^{\circ} \geq \theta$ & $20^{\circ} \geq \theta>10^{\circ}$ & $\theta>20^{\circ}$ \\
\hline Spark $750^{\circ} \mathrm{C}$ & $9(12 \%)$ & $19(21 \%)$ & $59(67 \%)$ \\
Spark $880^{\circ} \mathrm{C}$ & $8(8.5 \%)$ & $30(31.1 \%)$ & $58(60.4 \%)$ \\
NIST CoMoCat & $39(15 \%)$ & $82(30 \%)$ & $148(55 \%)$ \\
\hline \hline
\end{tabular}



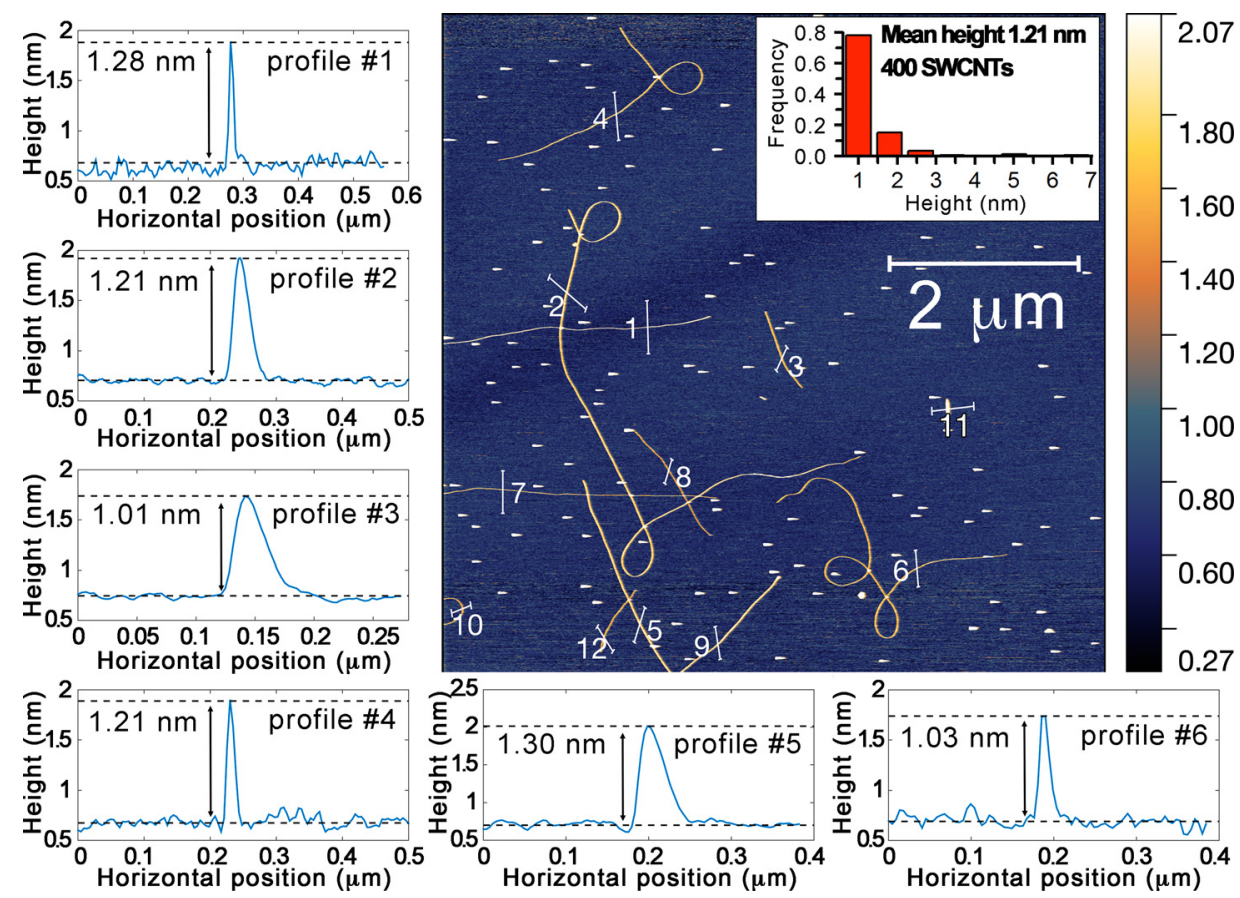

FIG. 4. AFM characterization of SWCNTs synthesized at $880^{\circ} \mathrm{C}$ with $\mathrm{N}$ $\approx 10^{5} \mathrm{~cm}^{-3}$. The scan window size is $7 \times 7 \mu \mathrm{m}^{2}$. The vertical height profiles of the cross sections 1-6 are shown around the scan window, representing heights between 1 and $1.3 \mathrm{~nm}$ (profiles $7-12$ can be found in Ref. 14). The histogram shows the statistics of 400 height profiles, with the mean at $1.21 \mathrm{~nm}$. identically distributed to the TEM data, as is evident by comparing the histograms in Figures 4 and 3(e).

Optical absorption spectroscopy (Lambda 950 spectrometer, PerkinElmer, Inc., USA) was used to further characterize the properties of SWCNTs. For optical measurements, the SWCNTs were collected on nitrocellulose membrane filters (Millipore, France) and press-transferred ${ }^{8}$ onto $1 \mathrm{~mm}$ thick quartz windows. The background-subtracted optical absorption spectra are shown in Figure 5(a). Fitting ${ }^{22}$ the spectra yielded geometric mean diameters of $1.05 \mathrm{~nm}$ and $1.13 \mathrm{~nm}$ for the SWCNTs grown at $750^{\circ} \mathrm{C}$ and $880^{\circ} \mathrm{C}$, a)
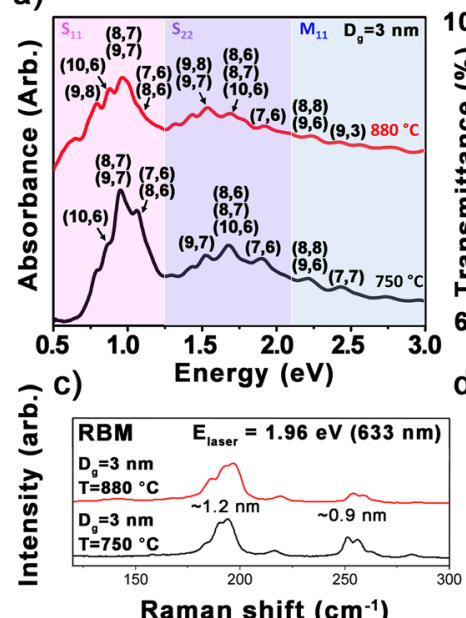

Raman shift $\left(\mathrm{cm}^{-1}\right)$ b)

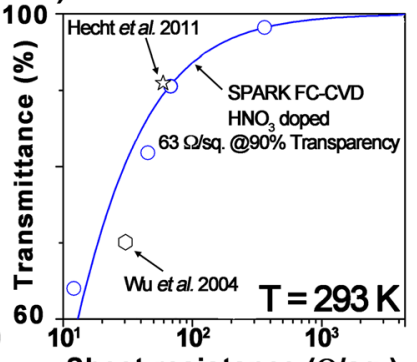

d) Sheet resistance ( $\Omega / s q$.

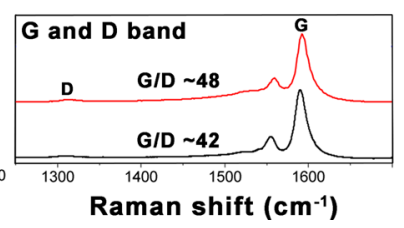

FIG. 5. Optical properties of the synthesized SWCNTs. (a) Optical absorption spectra of the SWCNTs synthesized at 750 and $880^{\circ} \mathrm{C}$, showing prominent and sharp resonant transition peaks dominated by $(7,6),(8,6)$, and $(8,7)$ chiralities in the $750^{\circ} \mathrm{C}$ sample and $(8,7),(9,7)$, and $(9,8)$ in the $880^{\circ} \mathrm{C}$ sample. $S_{11}, S_{22}$, and $M_{11}$ represent the energy ranges of the lowest-energy semiconducting, second-lowest energy semiconducting, and lowest-energy metallic absorption peaks, respectively. (b) The electro-optical performance of $\mathrm{HNO}_{3}$-treated spark FC-CVD tubes with $63 \Omega / \square$ sheet resistance at a $90 \%$ transparency measured at ambient conditions and at the $550 \mathrm{~nm}$ wavelength. (d) RBMs and (e) G and D bands of the SWCNTs grown at $750{ }^{\circ} \mathrm{C}$ and $880^{\circ} \mathrm{C}$ excited by a $633 \mathrm{~nm}$ laser. respectively, in excellent agreement with the TEM measurements (Figure 3(f)). The fitted diameter distributions can be found in Ref. 14. The very well resolved optical transition peaks in the spectra indicate a high fraction of individual SWCNTs and relatively narrow chirality distributions. The most prominent absorption peaks (Figure 5(a)) show that the $(7,6),(8,6)$, and $(8,7)$ species dominate in $750{ }^{\circ} \mathrm{C}$ sample, whereas the $(8,7),(9,7)$, and $(9,8)$ chiralities are strongly represented in the $880^{\circ} \mathrm{C}$ sample. Resonant Raman measurements (Labram HR spectroscope, Horiba Ltd., Japan) with a laser wavelength of $633 \mathrm{~nm}$ further verified that the tubes were of very high quality. This was indicated by high G/D intensity ratios ${ }^{23}$ between $\sim 42$ and $\sim 48$, shown in Figures 5(c) and 5(d), along with intense radial breathing modes (RBMs). Due to the reverse relationship of RBM frequency and diameter, a shift of Raman RBM intensities towards higher frequency in the lower temperature sample indicates smaller tube mean diameters, again in good agreement with TEM and optical absorption measurements. ${ }^{24}$

Finally, to demonstrate the application potential of the spark technique, TCFs out of $4 \mu \mathrm{m}$ long individual tubes were fabricated using press-transfer and treated with a strong solution of nitric acid $\left(\mathrm{HNO}_{3}\right)$. Figure 5(b) shows a performance of $63 \Omega / \square$ at $90 \%$ transparency for $550 \mathrm{~nm}$ light at ambient conditions, being among the best values reported for CNT TCFs. ${ }^{25}$ The substrate contribution was subtracted by placing a clean quartz window to the reference beam path, and the sheet resistances evaluated with a Jandel Ltd. 4-point probe at a $60 \mathrm{~g}$ needle loading. We note that while films of $90 \%$ transparency with a diameter of a few centimeters take several hours to deposit with the current small-scale reactor, prospects for scaling up the setup are quite straightforward.

To summarize, we have described a unique floating catalyst system for the synthesis of mostly individual, long and small diameter SWCNTs with narrow chiral angle distributions. The chiralities were clustered around $(7,6)$ and $(8,6)$ at a synthesis temperature of $750^{\circ} \mathrm{C}$ and $(8,7)$ and $(9,6)$ at 
$880^{\circ} \mathrm{C}$, with up to $70 \%$ of tubes having chiral angles between $20^{\circ}$ and $30^{\circ}$. The high SWCNT individuality was achieved after Brownian diffusion was identified as the primary cause for CNT bundle formation in the gas phase and prevented by limiting the CNT number concentration to $\sim 10^{5} \mathrm{~cm}^{-3}$. Therefore, especially in the floating catalyst routes, the controllability of the catalyst number concentration is essential, dictating the morphology of the end product all the way from individual tubes to large bundles. A high level of individual nanotubes can only be achieved by accepting a trade-off with the rate of CNT production. We have shown that at reactor number concentrations around $10^{5} \mathrm{~cm}^{-3}$, a fraction of up to $80 \%$ of individual SWCNTs can be achieved on surfaces-a figure that is likely reduced from the gas phase proportion by collisions during deposition. The production rate remains acceptable, though certainly depending on the choice of application; a greater yield is necessary for bulk production. Nevertheless, even with the current capacity, we demonstrated the fabrication of transparent conductive films with a record high performance of $63 \Omega / \square$ at $90 \%$ transparency, highlighting the application potential of our spark FC-CVD system. Besides transparent conductors, SWCNTs for many specific applications such as field effect transistors, nano-electromechanical systems, and quantum oscillators can readily be realized with the current system even at concentrations well below $10^{5} \mathrm{~cm}^{-3}$, potentially producing close to $100 \%$ of as-deposited individual tubes.

The research leading to these results has received funding from the European Union Seventh Framework Programme (FP7/2007-2013) under Grant Agreement Nos. 604472 (IRENA project) and 314068 (TREASORES project), by the Aalto Energy Efficiency (AEF) program through the MOPPI project and from TEKES projects CARLA and USG and Academy of Finland (HISCON No. 276160). A.G.N. was partially supported by the Ministry of Education and Science of the Russian Federation (Project doi: RFMEFI58114X0006) and T.S. by the Austrian Science Fund (FWF) through Grant No. M 1497-N19, by the Finnish Cultural Foundation, and by the Walter Ahlström Foundation. This work made use of the Aalto University Nanomicroscopy Center (Aalto-NMC) premises. The personnel of the National Nanomicroscopy Center of Aalto University are gratefully acknowledged for useful discussions and assistance.

${ }^{1}$ S. J. Tans, A. R. M. Verschueren, and C. Dekker, Nature 393(6680), 49 (1998).

${ }^{2}$ E. S. Snow, J. P. Novak, P. M. Campbell, and D. Park, Appl. Phys. Lett. 82(13), 2145 (2003).
${ }^{3}$ S. Sapmaz, Y. M. Blanter, L. Gurevich, and H. S. J. van der Zant, Phys. Rev. B 67(23), 235414 (2003); V. Sazonova, Y. Yaish, H. Ustunel, D. Roundy, T. A. Arias, and P. L. McEuen, Nature 431(7006), 284 (2004).

${ }^{4}$ J. Kong, H. T. Soh, A. M. Cassell, C. F. Quate, and H. Dai, Nature 395(6705), 878 (1998).

${ }^{5}$ J. L. Bahr, J. Yang, D. V. Kosynkin, M. J. Bronikowski, R. E. Smalley, and J. M. Tour, J. Am. Chem. Soc. 123(27), 6536 (2001); A. Garg and S. B. Sinnott, Chem. Phys. Lett. 295(4), 273 (1998).

${ }^{6}$ P. Nikolaev, M. J. Bronikowski, R. K. Bradley, F. Rohmund, D. T. Colbert, K. A. Smith, and R. E. Smalley, Chem. Phys. Lett. 313(1-2), 91 (1999); M. J. Bronikowski, P. A. Willis, D. T. Colbert, K. A. Smith, and R. E. Smalley, J. Vac. Sci. Technol. A 19(4), 1800 (2001).

${ }^{7}$ A. Moisala, A. G. Nasibulin, D. P. Brown, H. Jiang, L. Khriachtchev, and E. I. Kauppinen, Chem. Eng. Sci. 61(13), 4393 (2006).

${ }^{8}$ A. Kaskela, A. G. Nasibulin, M. Y. Timmermans, B. Aitchison, A. Papadimitratos, Y. Tian, Z. Zhu, H. Jiang, D. P. Brown, A. Zakhidov, and E. I. Kauppinen, Nano Lett. 10(11), 4349 (2010).

${ }^{9}$ D. Gonzalez, A. G. Nasibulin, S. D. Shandakov, H. Jiang, P. Queipo, A. S. Anisimov, T. Tsuneta, and E. I. Kauppinen, Chem. Mater. 18, 5052-5057 (2006).

${ }^{10}$ W. C. Hinds, Aerosol Technology: Properties, Behavior, and Measurement of Airborne Particles (Wiley-Interscience, 1999).

${ }^{11}$ S. H. Kim and M. R. Zachariah, Nanotechnology 16(10), 2149 (2005).

${ }^{12}$ G. Kasper, Aerosol Sci. Technol. 1(2), 187 (1982).

${ }^{13}$ S. Schwyn, E. Garwin, and A. Schmidt-Ott, J. Aerosol Sci. 19(5), 639 (1988).

${ }^{14}$ See supplementary material at http://dx.doi.org/10.1063/1.4926415 for CFD calculations, SWCNT length distributions, electron diffraction patterns, and SWCNT diameter distributions acquired by optical absorption and fitting.

${ }^{15}$ A. G. Nasibulin, A. Moisala, D. P. Brown, H. Jiang, and E. I. Kauppinen, Chem. Phys. Lett. 402(1-3), 227 (2005).

${ }^{16}$ D. Gonzalez, A. G. Nasibulin, A. M. Baklanov, S. D. Shandakov, D. P. Brown, P. Queipo, and E. I. Kauppinen, Aerosol Sci. Technol. 39(11), 1064 (2005).

${ }^{17}$ S. M. Bachilo, L. Balzano, J. E. Herrera, F. Pompeo, D. E. Resasco, and R. B. Weisman, J. Am. Chem. Soc. 125(37), 11186 (2003).

${ }^{18}$ S. M. Bachilo, M. S. Strano, C. Kittrell, R. H. Hauge, R. E. Smalley, and R. B. Weisman, Science 298(5602), 2361 (2002); C. Fantini, A. Jorio, M. Souza, M. S. Strano, M. S. Dresselhaus, and M. A. Pimenta, Phys. Rev. Lett. 93(14), 147406 (2004).

${ }^{19}$ Y. Tian, H. Jiang, I. V. Anoshkin, L. J. I. Kauppinen, K. Mustonen, A. G. Nasibulin, and E. I. Kauppinen, "A census of chirality population in a NIST reference material of single-walled carbon nanotubes," ACS Nano (submitted).

${ }^{20}$ A. Jorio, A. P. Santos, H. B. Ribeiro, C. Fantini, M. Souza, J. P. M. Vieira, C. A. Furtado, J. Jiang, R. Saito, L. Balzano, D. E. Resasco, and M. A. Pimenta, Phys. Rev. B 72(7), 075207 (2005).

${ }^{21}$ H. W. C. Postma, A. Sellmeijer, and C. Dekker, Adv. Mater. 12(17), 1299 (2000).

${ }^{22}$ Y. Tian, H. Jiang, J. V. Pfaler, Z. Zhu, A. G. Nasibulin, T. Nikitin, B. Aitchison, L. Khriachtchev, D. P. Brown, and E. I. Kauppinen, J. Phys. Chem. Lett. 1(7), 1143 (2010).

${ }^{23}$ I. W. Chiang, B. E. Brinson, R. E. Smalley, J. L. Margrave, and R. H. Hauge, J. Phys. Chem. B 105(6), 1157 (2001).

${ }^{24}$ A. Jorio, R. Saito, G. Dresselhaus, and M. S. Dresselhaus, Philos. Trans. R. Soc., London, Ser. A 362(1824), 2311 (2004).

${ }^{25}$ Z. Wu, Z. Chen, X. Du, J. M. Logan, J. Sippel, M. Nikolou, K. Kamaras, J. R. Reynolds, D. B. Tanner, A. F. Hebard, and A. G. Rinzler, Science 305(5688), 1273 (2004); D. S. Hecht, A. M. Heintz, R. Lee, L. Hu, B. Moore, C. Cucksey, and S. Risser, Nanotechnology 22(7), 075201 (2011). 